\title{
Characterization of VOC emission profile of different wood species during moisture cycles
}

\author{
Martina Sassoli ${ }^{(1)}$, \\ Cosimo Taiti ${ }^{(2)}$, \\ Werther Guidi Nissim ${ }^{(2)}$, \\ Corrado Costa ${ }^{(3)}$, \\ Stefano Mancuso (2), \\ Paolo Menesatti ${ }^{(3)}$, \\ Marco Fioravanti ${ }^{(i)}$
}

\begin{abstract}
This study addresses the characterization of volatile organic compounds (VOCs) emitted by samples of 13 different wood species, belonging to both softwoods and hardwoods groups, regularly measured at different intervals of time, after the first measurement on green wood. The same wood specimens were subjected to several cycles of water desorption and adsorption, assuming that moisture variation might play a role in both the formation and emission of VOCs. Proton Transfer Reaction-Time of Flight-Mass Spectrometry (PTR-TOFMS) was used as a tool to characterize the emission of VOCs. Coupled with a multivariate class-modelling approach, this tool was able to discriminate between groups (softwood and hardwood) and in some cases between different species. However, results showed that the discriminant capacity of VOCs emission to separate species and families rapidly decreases after the first cycles of moisture variation in wood. The green wood was characterized by a richness of volatile compounds, whereas, after only the first dry cycle, wood emitted a more restricted group of compounds. We hypothesized that most of these VOCs might have originated from structural changes and degradation processes that involve the main polymers (particularly hemicellulose) constituting the cell wall of wooden cells. The results obtained are in agreement with the physical and chemical modification processes that characterize wood ageing.
\end{abstract}

Keywords: Wood, VOCs, PTR-TOF-MS, PLSDA, Wood Ageing, Moisture Content

carbons, and oxygenated compounds, with vegetative emissions typically being composed of alkenes (such as isoprene, monoterpenes, and sesquiterpenes) and oxygenated VOCs (including acetone and methanol - Atkinson \& Arey 2003).

The classification proposal of the World Health Organization (WHO 1989) is the most widely used. The WHO classifies pollutants into very volatile organic compounds (VVOCs), volatile organic compounds (VOCs), semi-volatile compounds (SVOCs), and organic compounds associated with particulate matter (POM).

The emission from vegetation (biogenic emission) has been widely studied: condi-

(1) Università degli Studi di Firenze, Dipartimento di Gestione dei Sistemi Agrari, Alimentari e Forestali (GESAAF), v. San Bonaventura 13, I-50145 Firenze (Italy); (2) Università degli Studi di Firenze, Dipartimento di Scienze delle Produzioni Agroalimentari e dell'Ambiente, v.le delle Idee 30, I-50019 Sesto Fiorentino, Firenze (Italy); (3) Consiglio per la ricerca in agricoltura e l'analisi dell'economia agraria (CREA) - Unità di ricerca per l'ingegneria agraria, v. del Pascolare 16, I-00015 Monterotondo Scalo (RM - Italy)

@ Martina Sassoli (martina.sassoli@unifi.it)

Received: Oct 19, 2016 - Accepted: Mar 29, 2017

Citation: Sassoli M, Taiti C, Guidi Nissim W, Costa C, Mancuso S, Menesatti P, Fioravanti M (2017). Characterization of VOC emission profile of different wood species during moisture cycles. iForest 10: 576-584. - doi: 10.3832/ifor2259-010 [online 2017-05-08]

tions that have been explored include diurnal and seasonal variations (Grabmer et al. 2006, Karl et al. 2003) in response to temperature changes (Filella et al. 2007) and to different environmental conditions (Holzinger et al. 2000).

VOC emissions are also present in wood, and they are dependent upon many factors including species, age, and $\mathrm{pH}$ value; these emissions differ significantly between hardwoods and softwoods (Taiti et al. 2016, Roffael et al. 2015, Steckel et al. 2010, Roffael 2006). Specifically, Fengel \& Wegener (1989) reported that softwood polyoses contain higher amounts of mannose and galactose than hardwoods, whereas hardwoods are richer in pentoses, characterized by higher amounts of acetyl groups. VOCs from wood can originate either from compounds present in the native structure of wood, or through different chemical processes, such as oxidation and hydrolysis, that involve wood components (Roffael et al. 2015). In general, the most common VOCs emitted from wood are terpenes, aliphatic aldehydes, and organic acids (Schumann et al. 2012). Terpenes are the main constituent of the resin of softwoods, and aldehydes are formed by oxidative decay of fatty acids. Among the organic acids, acetic acid occurs due to cleavage of acetyl groups from hemicelluloses, whereas hexanoic acid originates from the decay of fatty acids. Furthermore, by increasing the time of storage and modi- 
Tab. 1 - List of specimens studied.

\begin{tabular}{cllll}
\hline $\begin{array}{c}\text { Code } \\
\text { no. }\end{array}$ & Species & $\begin{array}{l}\text { Species } \\
\text { Acronym }\end{array}$ & Family & Group \\
\hline 1 & Atlantic cedar (Cedrus atlantica Man.) & CA & Pinaceae & Softwood \\
2 & Austrian black pine (Pinus nigra Arn.) & PiN & Pinaceae & Softwood \\
3 & Common cypress (Cupressus sempervirens L.) & CS & Cupressaceae & Softwood \\
4 & Bay laurel (Laurus nobilis L.) & LN & Lauraceae & Hardwood \\
5 & European walnut (Juglans regia L.) & JR & Juglandaceae & Hardwood \\
6 & Black poplar (Populus nigra) & PoN & Salicaceae & Hardwood \\
7 & Common fig (Ficus carica L.) & FC & Moraceae & Hardwood \\
8 & Almond (Prunus amygdalus (Mill.) D.A.Webb) & PAmy & Rosaceae & Hardwood \\
9 & Wild cherry (Prunus avium L.) & PAv & Rosaceae & Hardwood \\
10 & Black locust (Robinia pseudoacacia L.) & RP & Fabaceae & Hardwood \\
11 & Turkey oak (Quercus cerris L.) & QC & Fagaceae & Hardwood \\
12 & Downy oak (Quercus pubescens Willd.) & QP & Fagaceae & Hardwood \\
13 & Evergreen oak (Quercus ilex L.) & QI & Fagaceae & Hardwood \\
\hline
\end{tabular}

fying the conditions of wood storage, the release of some VOCs declines dramatically over time, reaching very low emission levels (e.g., terpenes in softwoods and formaldehyde in both soft- and hardwoods are naturally occurring chemicals in wood Roffael 2006), whereas specific treatments could determine the transformation of the originals VOCs from wood, changing their release rates (Manninen et al. 2002, Hyttinen et al. 2010). In addition, during storage the composition of extractives changes: the content of extractives decreases whilst free sugar, lipophilic fats, fatty and resin acids, and sterols substantially decreases (Salem \& Böhm 2013).

Previous studies have already dealt with products that derived from the degradation of wood polysaccharide fraction, after specific treatments or processing procedures of wood, showing the formation of compounds such as: (1) formaldehyde, acetaldehyde, propenal, butanal, and butanone resulting from the breakdown of the polysaccharide fraction of the wood during pyrolysis (Salem \& Böhm 2013); (2) acetic acid following acetyl group hydrolysis in hemicellulose (Risholm-Sundman et al. 1998); (3) pentanal, hexanal, and other al2009). were: of the sample); dehydes resulting from the oxidation of unsaturated fatty acids of triglycerides ( $\mathrm{Ri}$ sholm-Sundman et al. 1998); (4) furfural due to hydrolysis of carbohydrates (Roffael et al. 2015); and (5) furan and furan derivatives as thermal degradation products of cellulose and other polysaccharides (Manninen et al. 2002, Fernández de Simón et al.

In the literature, no studies have been carried out on green wood (i.e., measured before the first drying cycle) and subsequently repeated on the same samples at regular intervals of time after wood moisture cycles. Assuming that moisture cycles could have an effect in VOC formation and emission, having an active (hydrolysis) or passive (carrier) role in such phenomena described as wood ageing (i.e., change in the chemical composition of constitutive polymers), the aims of the present study

- assessing the VOCs emitted by the wood of different species in the green condition (e.g., immediately after tree felling or increment cores sampling) and over the time in response to several conditioning cycles (e.g., variation of moisture content

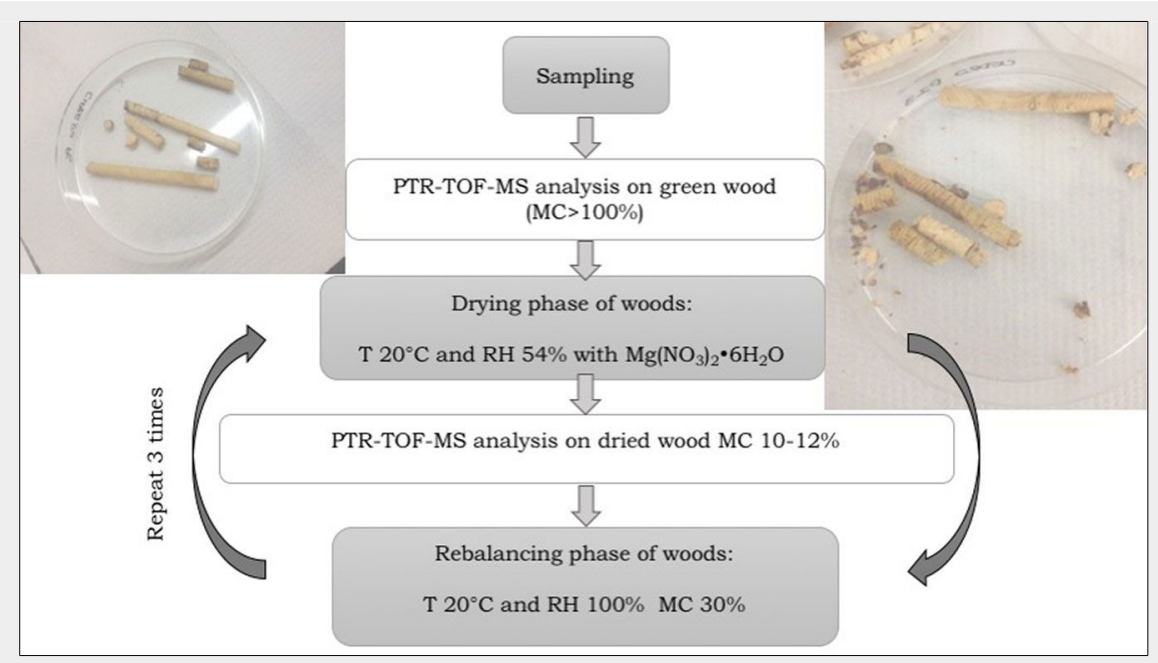

Fig. 1 - Scheme of the experimental procedure.
- estimating the possibility to use VOC emission as a discriminant between different wood taxaafter ageing (e.g., after repetition of different cycles of moisture variation); and

- evaluating whether VOC compounds yield information about the processes of wood modification occurring during wood ageing.

PTR-TOF-MS, used to characterize these emissions, is a useful analytical technique largely applied in order to provide an overview of the mass spectra of volatile compounds emitted by different materials (Vita et al. 2015, Mancuso et al. 2015, Soukoulis et al. 2013, Cappellin et al. 2013, Han et al. 2010). A detailed description of the PTRTOF-MS tool is discussed by Blake et al. (2009).

\section{Material and methods}

\section{Study area and sampling design}

Sampling procedures including site and species description have been thoroughly described elsewhere (Taiti et al. 2016). The list of the species studied is reported in Tab. 1. The specimens, mainly constituted by increment cores, originated from the same plant and made up of both heartwood and sapwood, were analysed in the green condition and after several cycles of moisture variation.

\section{Moisture cycles}

The first VOC analysis was performed by PTR-TOF-MS on green state increment cores (indicated as measurement time T1). Subsequently, samples were submitted to three moisture cycles from fiber saturation point (FSP) to a moisture content (MC) of $10-12 \%$, which were intended to simulate the natural ageing of wood through cycles of moisture variation that typically occur in wood during this process (Akahoshi \& Obotaya 2015). Emissions were regularly measured at different intervals of time on samples with moisture content of 10-12\% (measurement times $\mathrm{T}_{2}, \mathrm{~T}_{3}$, and $\mathrm{T}_{4}$ ).

The following drying-moistened conditioning schedules were followed:

- for T2 analysis (day 7): all the samples were placed in a sealed basin (volume: 72 I) for 7 days and dried with magnesium nitrate hexahydrate for analysis (EMSURE $^{\oplus}$ ACS, Reag. Ph Eur. CAS 13446-18-9, EC Number 233-826-7, chemical formula $\mathrm{Mg}\left(\mathrm{NO}_{3}\right)_{2} \cdot 6 \mathrm{H}_{2} \mathrm{O}$ at T $20{ }^{\circ} \mathrm{C}$ (obtaining a $\mathrm{RH}$ $54 \%-58 \%$ ) until no weight loss was detected and a moisture content (MC) of 10$12 \%$ was achieved for the analysis of emissions;

- for T3 and T4 analysis: subsequently, the increment cores were moistened at $\mathrm{T} 20$ ${ }^{\circ} \mathrm{C}$ and $\mathrm{RH} 100 \%$ in the same basin for 7 days and submitted to another drying cycle with $\mathrm{Mg}\left(\mathrm{NO}_{3}\right)_{2} \cdot 6 \mathrm{H}_{2} \mathrm{O}$ for 7 additional days. At the end of the drying phase, samples were analysed by PTR-TOF-MS (T3, day 21). The same procedure was applied for T4 measurement (day 35 - Fig. 1). 
Soxhlet extraction and UV treatment of core samples

In order to assess whether the emissions were due to, or influenced by, the presence of extractives in wood or to the microbiological activity (bacteria), a supplementary set of Norway spruce samples was prepared. One sub-sample was extracted in alcohol, whereas a second subsample was subjected to UV radiation, maintaining for each test an untreated sample as control. Extractives were removed by means of Soxhlet extraction in ethanol (96\%), according to standard prescription (TAPPI T 204 om-88), but without the grinding stage. The other specimen was exposed to UV treatment (Sankyo DenKi G20T10 ${ }^{\oplus}$ lamp, 20 Watt) for 1 hour, in order to eliminate possible microbiological organisms.

At the end of these treatments, all the specimens, treated and control, were analysed by PTR-TOF-MS.

\section{PTR-TOF-MS and VOCs analysis}

The real-time detection of VOCs emitted by different wood cores was achieved using a PTR-TOF $8000^{\circledR}$ system (Ionicon Analytik Innsbruck, Austria). The same samples were analysed again with the same equipment to monitor the VOCs' profiles in response to subsequent ageing cycles. All VOCs emitted by the samples were assessed using a setup previously reported in Taiti et al. (2016). Before analysing the samples, an empty jar was measured. The inlet flow was set at $100 \mathrm{sccm}$. The headspace analysis was recorded in a range between $\mathrm{m} / \mathrm{z} 20-210$ for $60 \mathrm{~s}$ with an acquisition rate of one spectrum per second. All of the measurements were carried out under the following drift tube conditions: $600 \mathrm{~V}$ drift voltage, $60{ }^{\circ} \mathrm{C}$ temperature, and pressure of $2.23 \mathrm{mbar}$, resulting in an $\mathrm{E} / \mathrm{N}$ value (electric field strength/gas number density) of 130 Townsend $\left(\mathrm{Td}, 1 \mathrm{Td}=10^{-17} \mathrm{~cm}^{2} / \mathrm{V} \mathrm{s}\right)$.

\section{PTR-TOF-MS data analysis}

The raw data were acquired by the TOFDAQ Viewer ${ }^{\oplus}$ software (Tofwerk AG, Thun, Switzerland). Data acquisition and quantification of peaks, expressed as normalized count for seconds (ncps), were corrected according to the duty cycle, and the signals were normalized to the primary ion signal (cps $\rightarrow$ ncps - Herbig et al. 2009). To allow a rapid identification of compounds with a high level of confidence, the internal calibration of mass spectral data was based on three points calibration using $\mathrm{m} / \mathrm{z}=21.022$ $\left(\mathrm{H}_{3} \mathrm{O}^{+}\right), \mathrm{m} / \mathrm{z}=59.049\left(\mathrm{C}_{3} \mathrm{H}_{7} \mathrm{O}^{+}\right)$, and $\mathrm{m} / \mathrm{z}=$ $137.132\left(\mathrm{C}_{10} \mathrm{H}_{17}{ }^{+}\right)$; this was performed off-line (Lanza et al. 2015). The tentative identification of VOCs provided by the tool (high sensitivity and with a fast selective identification) was compared on models of fragmentation available in the literature and compared with published VOCs emitted by wood species (Tab. S1 in Supplementary material). Dead time correction and peak extraction were performed according to a procedure described elsewhere using a modified Gaussian peak shape (Cappellin et al. 2011). Subsequently, the peaks associated with the PTR-MS ion source including $\mathrm{m} / \mathrm{z}=32\left(\mathrm{O}_{2}{ }^{+}\right)$and $\mathrm{m} / \mathrm{z}=37$ (water cluster ion) were eliminated.

\section{Statistical analysis}

The matrix composed by 80 VOCs $\times 156$ wood samples ( 13 species; 4 measurement times $\mathrm{T} 1, \mathrm{~T} 2, \mathrm{~T} 3, \mathrm{~T} 4 ; 3$ replicates each) was used to assess the potential of the method to discriminate: (i) between softwoods and hardwoods (2 groups); (ii) among families (9 groups); and (iii) among plant species (13 groups). Three class-modelling approaches were applied to predict the aforementioned groups: (i) the model $\mathrm{M}_{1}$ built on the first measurement dataset ( $\mathrm{T} 1$ ); (ii) the model $\mathrm{M} 2$ built on the fourth measurement dataset ( $\mathrm{T}_{4}$ ); and (iii) the model $M_{3}$ that include all the measurement datasets ( $\left.T_{1}, T_{2}, T_{3}, T_{4}\right)$. Matrices at each time were separately autoscaled by column.

After this procedure, the matrix was preprocessed using the normalization algorithm (which performed normalization of the rows; i.e., samples). A partial least squares discriminant analysis (PLSDA) approach was applied for the classification of the matrix to determine hardwoods and softwoods or the 13 species using the VOCs. The models were developed using a procedure written in the MATLAB 7.1 R14 environment. PLSDA (Sjöström et al. 1986, Sabatier et al. 2003, Infantino et al. 2015) is a PLS regression (SIMPLS algorithm - De Jong 1993) in which the response variable is categorical, expressing the class membership of the statistical units. The objective of PLSDA is to find a model, developed from a training set of observations of known class membership, that separates classes of objects on the basis of their Xvariables. The percentages of correct classification were calculated for the calibration and validation phases, and then used for model selection. The PLSDA model selection was mainly based on the efficiencies and robustness parameters described above. For $\mathrm{M}_{1}$ and $\mathrm{M}_{2}, \mathrm{~T}_{1}$ and $\mathrm{T}_{4}$ were respectively used as the calibration and validation sets, and the rest of the samples as the test set; for $M_{3}$, the dataset was divided into a calibration/validation set composed by $66.67 \%$ of samples and an internal validation set represented by the remaining $33.3 \%$. The partitioning of the models for $M_{3}$, which include all the sampling times, was conducted optimally by choosing the Euclidean distances based on the algorithm of Kennard \& Stone (1969) that selects objects without the a priori knowledge of a regression model. A summary of the relative importance of the $X$ variables for both $Y$ and $X$ model parts is given by Variable Importance in the Projection (VIP - Taiti et al. 2015, Infantino et al. 2015). VIP scores estimate the importance of each variable in the PLS-based models.
VIP scores were calculated according to Chong \& Jun (2005). The explanatory variables with VIP scores values larger than 1 tend to be more important than others, although this does not imply that a variable with a low VIP score is not relevant for the model.

\section{Results and discussion}

Several mass peaks in the range of measured masses $(\mathrm{m} / \mathrm{z}=20-210)$ were collected from 13 different wood species at four different sampling times; 80 mass peaks were detected in the specimens from the first measurement (Taiti et al. 2016), but their number subsequently decreased after several ageing cycles. In Tab. S1 (Supplementary material) are reported the most significant putative molecules identified in the first analysis from wood in the green condition, including their measured $\mathrm{m} / \mathrm{z}$ ratio, protonated molecular formula, chemical name, and related reference. The signals observed from green specimens varied in terms of the nature and intensity for each wood species.

According to our tentative identification, the main compounds detected were $\mathrm{m} / \mathrm{z}=$ 33.033 methanol, $\mathrm{m} / \mathrm{z}=45.033$ acetaldehyde, $\mathrm{m} / \mathrm{z}=47.049$ ethanol, $\mathrm{m} / \mathrm{z}=59.049$ acetone, $\mathrm{m} / \mathrm{z}=61.028$ acetic acid, $\mathrm{m} / \mathrm{z}=$ 69.036 furan, $\mathrm{m} / \mathrm{z}=81.069$ monoterpene fragment, $m / z=93.070$ toluene or $p$-cymene fragment, $\mathrm{m} / \mathrm{z}=153.127$ terpenoid compound, $\mathrm{m} / \mathrm{z}=137.132$ monoterpenes, and $\mathrm{m} / \mathrm{z}=205.195$ sesquiterpenes. All these compounds were recorded in all the investigated species during the first measurement (Tab. S1 in Supplementary material). Their emission rates were successively monitored three times during the ageing of specimens (Fig. 2 and Fig. 3).

All the VOCs emissions taken into account decreased in intensity starting from the second analysis (after the first drying of wood), and they subsequently disappeared after the second and third steps, excluding some VOCs that continued to be emitted in minimum quantities by some species. For instance, Pinus nigra and Cupressus sempervirens showed the highest signal intensity and the highest number of total peaks in softwood during first sampling time (Fig. 2 and Fig. 3, Tab. S1 in Supplementary material), but in the subsequent analysis, only their emission rates of acetaldehyde and acetone were slightly higher in comparison with all other VOC species. More generally, the softwoods group (Cedrus, Pinus, and Cupressus) continued to emit more methanol than the hardwoods group.

Fresh hardwood species released higher amounts of acetic acid, probably originating from the hydrolyses of acetyl groups in hemicellulose, than terpenes compounds (Fig. 2 and Fig. 3). Regarding specific profile emission from hardwoods during ageing, only Populus nigra and Ficus carica showed ethanol emission even though in very low amounts, differentiating them from the other hardwood and softwood 


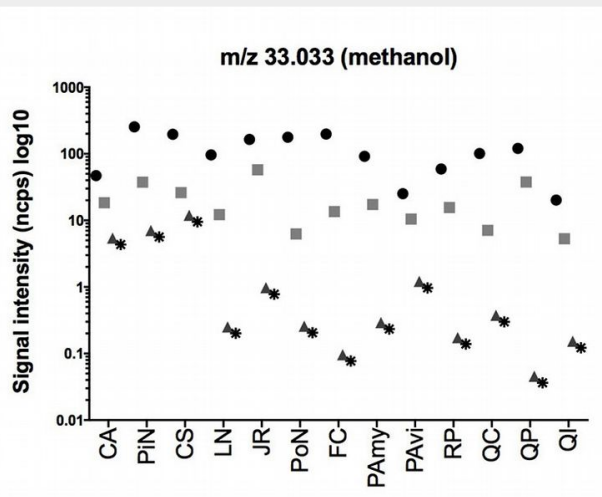

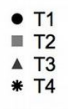

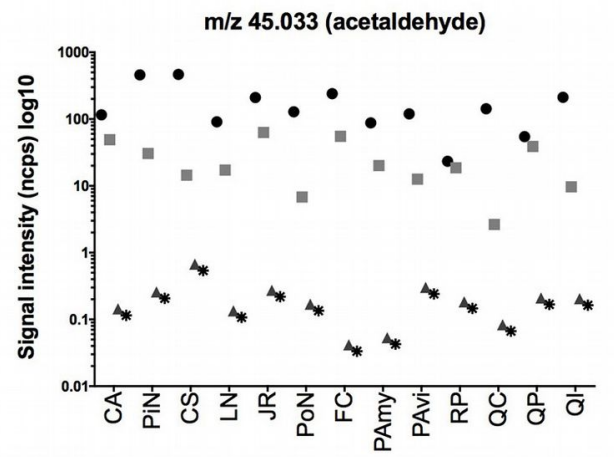

T2 intensity of some com-

T3 4 pounds (reported by $\mathrm{m} / \mathrm{z}$ ratio) detected in the 13 analysed species. Different symbols indicate a different time analysis ( $\mathrm{T} 1 \mathrm{for}$ green state wood, whereas $\mathrm{T}_{2}, \mathrm{~T}_{3}$ and $\mathrm{T}_{4}$ for samples after moisture cycles). Species acronyms $(x$-axis) are reported in Tab. 1.
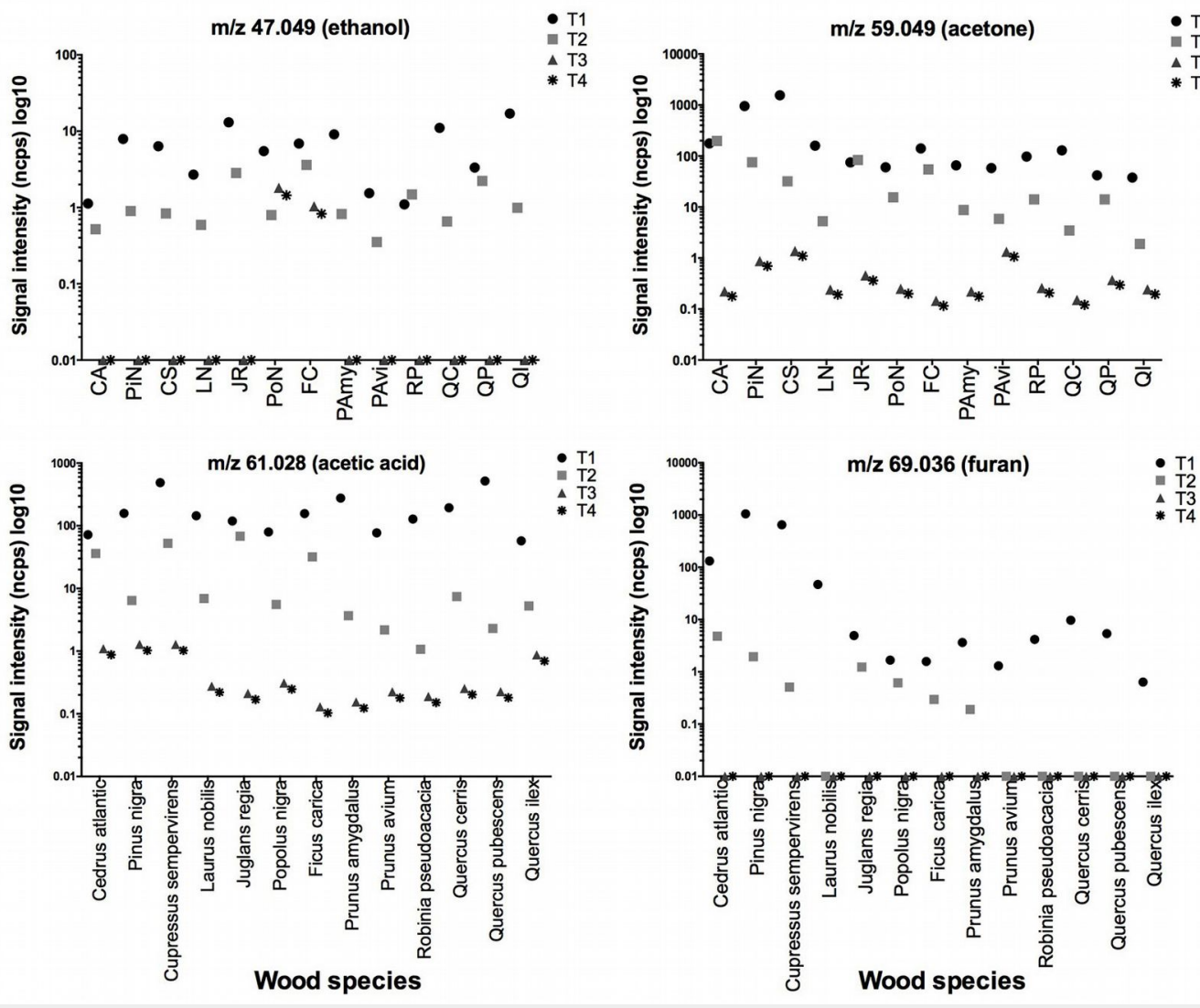

species here examined.

The emission intensity of compounds tentatively identified as terpenes, terpenoids, sesquiterpenes, and their fragments $(\mathrm{m} / \mathrm{z}=$ 81.069; 93.070; 153.127; 137.132; 205.195) was higher in softwoods (Cedrus, Pinus, and (Cupressus) in comparison with most hardwood species (Fig. 3), with terpene compounds being the essential part of the resin composition in many softwood species (Risholm-Sundman et al. 1998, Baumann et al. 1999, Schumann et al. 2012, Roffael et al. 2015). The only exception was represented by Bay laurel (Laurus nobilis) that showed similar peak intensities for the masses regarding terpenes, due to the richness of such compounds in this species (e.g., oxygenated monoterpenes and monoterpene hydrocarbons - Flamini et al. 2007). However, given that terpenes are very volatile, their intensity decreased drastically by the second analysis, and, in the following cycles, terpene fragments and monoterpenes $(\mathrm{m} / \mathrm{z} 81.070$ and $\mathrm{m} / \mathrm{z} 137.132$, respectively) were recorded only in softwoods, especially in Black pine (Pinus nigra).

The comparison of the emission profiles of extracted and UV-treated samples with reciprocal control samples showed no significant changes in the observed emitted compounds. This finding seems to indicate that all the revealed emissions have to be attributed to modification processes occurring in wood and in its constitutive polymers, avoiding the hypothesis of possible interference in the results due to the presence of extractives or because of microbiological activity.

The statistical significance of the data sets measured at the different times ( $\mathrm{T} 1$ to T4) was tested according to the models previously described ( $\left.M_{1}, M_{2}, M_{3}\right)$.

The performance indicators of the PLSDA models $M_{1}$ and $M_{2}$ tested on the other measurement times are reported in Tab. 2 .
The M1 model adopted to discriminate hardwood vs. softwood samples using 3 Latent Vectors showed 0.98 and 0.93 mean sensitivity and specificity values, respectively. The mean classification error was 0.05 . The mean percentage of correct classification was determined to be equal to $100 \%$ for the calibration/validation set (at T1), whereas at T2 it decreased to $84.6 \%$, and at $\mathrm{T}_{3}$ and $\mathrm{T}_{4}$ to $79.5 \%$. The M1 model adopted to discriminate the 9 families used 15 Latent Vectors and showed 1 as the mean sensitivity and specificity values. The mean classification error was equal to 0 . Even in this case, the mean percentage of correct classification was equal to $100 \%$ for the calibration/validation set (at T1), while at T2 it steeply decreased to $10.3 \%$, and at $\mathrm{T}_{3}$ and $\mathrm{T} 4$ to $7.7 \%$. The $\mathrm{M}_{1}$ model that was adopted to discriminate the 13 species used 10 Latent Vectors and showed 1 as the mean sensitivity and specificity values. The mean classification error was equal to 0 . 
Fig. 3 - Evaluation of signal intensity of terpenes and terpenoid compounds detected in the 13 analysed species. Different symbols indicate a different time analysis ( $\mathrm{T} 1$ for green state wood, whereas $\mathrm{T}_{2}, \mathrm{~T}_{3}$ and $\mathrm{T} 4$ for samples after moisture cycles). Species acronyms ( $x$-axis) are reported in Tab. 1.
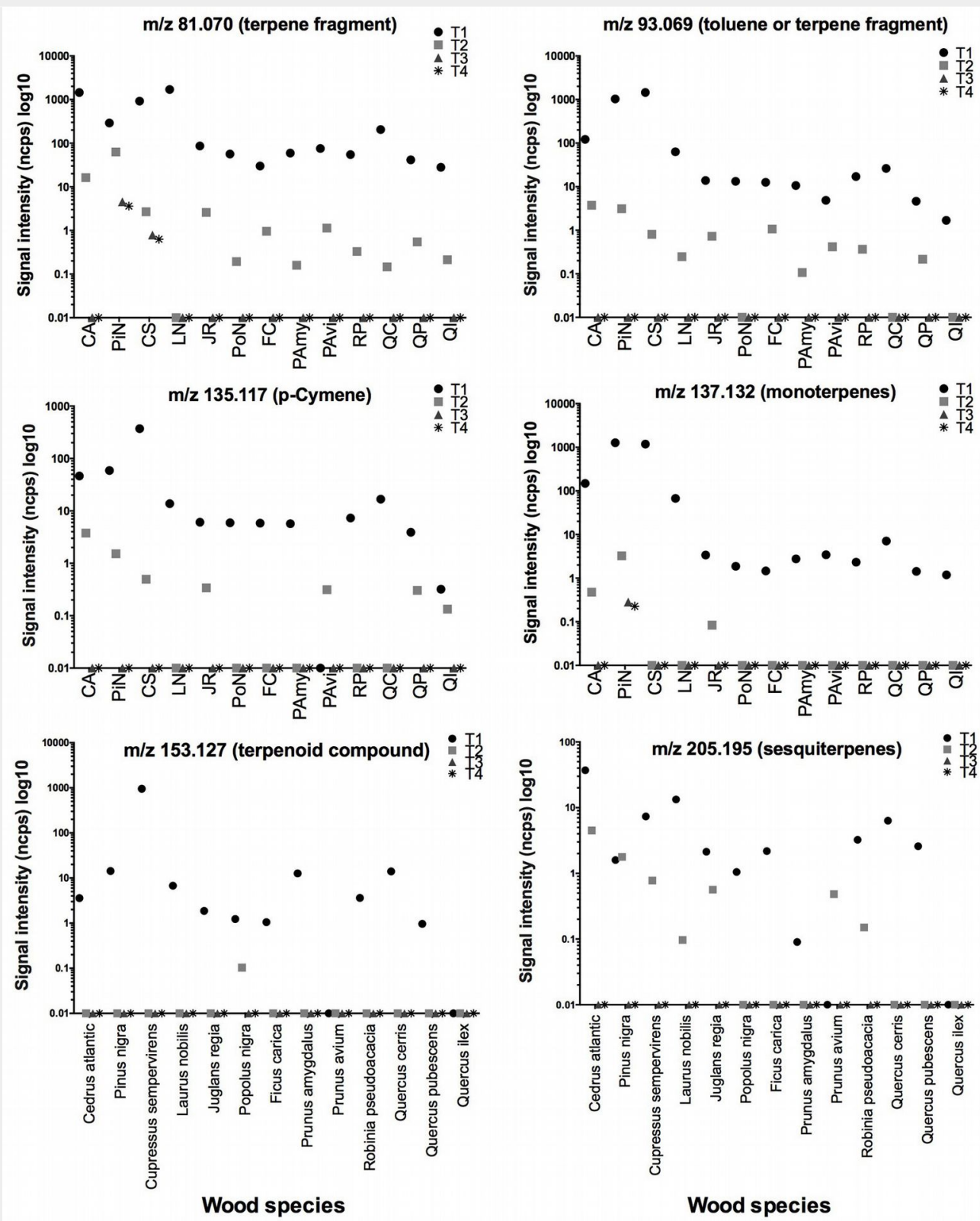

Wood species

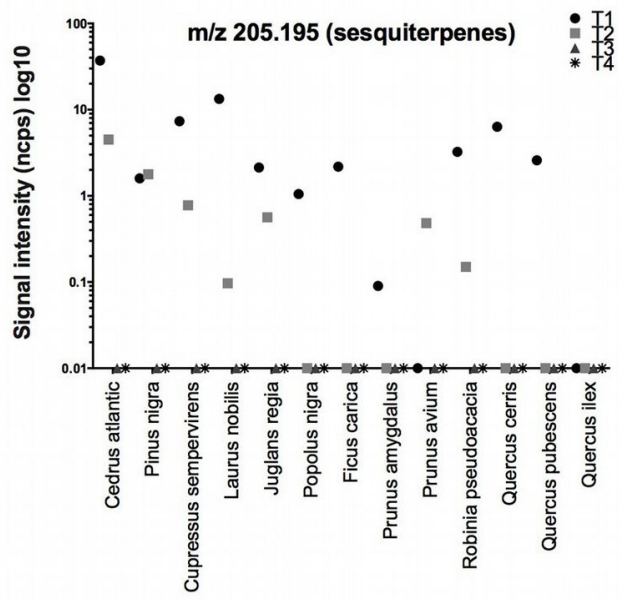

Tab. 2 - Characteristics and principal results of the three PLSDA models. (LVs): Latent Vectors; (RMSEC): Root Mean Square Error of Calibration.

\begin{tabular}{|c|c|c|c|c|c|c|c|c|c|}
\hline \multirow[b]{2}{*}{ Characteristics } & \multicolumn{3}{|l|}{ M1 } & \multicolumn{3}{|l|}{ M2 } & \multicolumn{3}{|l|}{ M3 } \\
\hline & $\begin{array}{l}\text { Hard/ } \\
\text { softwood }\end{array}$ & Families & Species & $\begin{array}{l}\text { Hard/ } \\
\text { softwood }\end{array}$ & Families & Species & $\begin{array}{l}\text { Hard/ } \\
\text { softwood }\end{array}$ & Families & Species \\
\hline No. samples model & 39 & 39 & 39 & 39 & 39 & 39 & 104 & 104 & 104 \\
\hline No. classes (y-block) & 2 & 9 & 13 & 2 & 9 & 13 & 2 & 9 & 13 \\
\hline No. LVs & 3 & 15 & 10 & 6 & 9 & 8 & 6 & 15 & 17 \\
\hline \% Cumulated variance $\mathrm{X}$-block & 70.32 & 99.33 & 97.37 & 84.45 & 97.6 & 94.95 & 77.56 & 88.62 & 90.88 \\
\hline$\%$ Cumulated variance Y-block & 68.15 & 85.1 & 71.15 & 65.59 & 51.13 & 50.55 & 32.24 & 48.67 & 45.6 \\
\hline Mean sensitivity (\%) & 0.98 & 1 & 1 & 1 & 0.9 & 1 & 1 & 0.88 & 0.89 \\
\hline Mean specificity (\%) & 0.93 & 1 & 1 & 0.98 & 0.95 & 0.94 & 1 & 0.93 & 0.93 \\
\hline Random probability (\%) & 50 & 11.11 & 7.69 & 50 & 11.11 & 7.69 & 50 & 11.11 & 7.69 \\
\hline Mean classification error (\%) & 0.05 & 0 & 0 & 0.01 & 0.08 & 0.03 & 0 & 0.1 & 0.1 \\
\hline Mean RMSEC & 0.4 & 0.12 & 0.14 & 0.41 & 0.22 & 0.19 & 0.52 & 0.23 & 0.2 \\
\hline $\begin{array}{l}\text { Mean \% correct classification } \\
\text { calibration/validation set }\end{array}$ & 100 & 100 & 100 & 100 & 84.62 & 80.77 & 100 & 82.69 & 78.85 \\
\hline No. samples test & 117 & 117 & 117 & 117 & 117 & 117 & 52 & 52 & 52 \\
\hline Mean \% correct classification test set & T2: 84.62 & T2: 10.26 & $\mathrm{~T} 2: 17.95$ & T1: 66.67 & T1: 7.69 & T1: 7.69 & 100 & 67.31 & 73.08 \\
\hline Mean \% correct classification test set & T3: 79.49 & T3: 7.69 & T3: 25.64 & T2: 84.62 & T2: 20.51 & T2: 20.51 & - & - & - \\
\hline Mean \% correct classification test set & T4: 79.49 & T4: 7.69 & T4: 25.64 & T3: 100 & T3: 79.49 & T3: 74.36 & - & - & - \\
\hline
\end{tabular}


Tab. 3 - Confusion matrix for $M_{3}$ families test set. Correct classification of wood samples are on the main diagonal of the matrix, while any value off the diagonal represents an incorrectly classified observation.

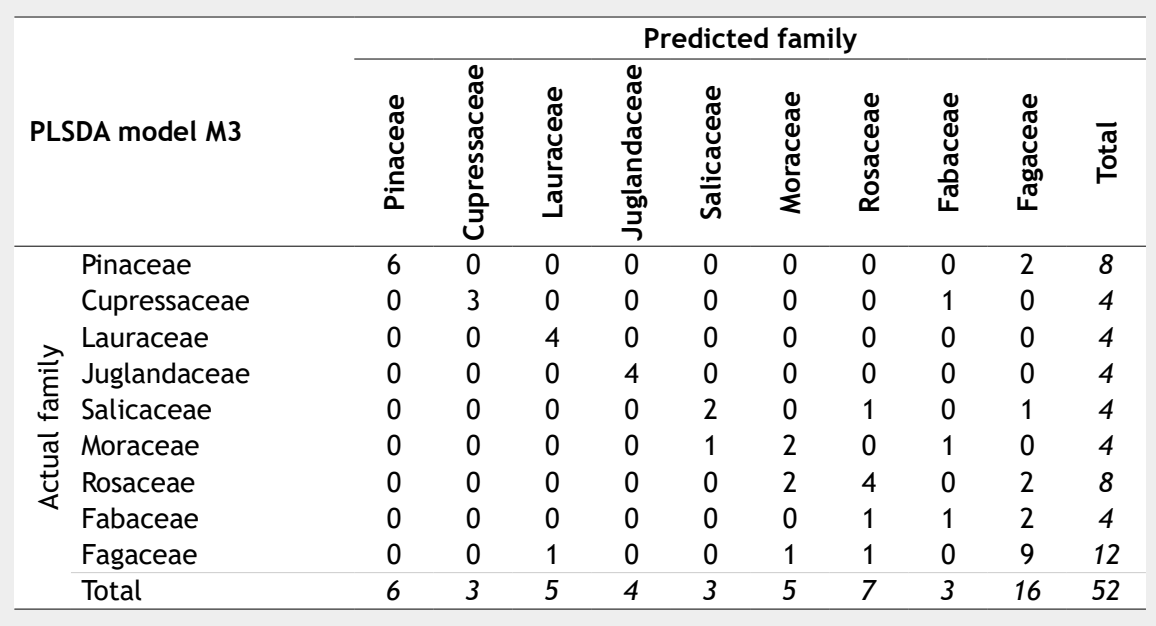

The mean percentage of correct classifications in this case was determined be equal to $100 \%$ for the calibration/validation set at $\mathrm{T} 1$, while at $\mathrm{T} 2$ it sharply decreased to $18.0 \%$, and at $\mathrm{T} 3$ and $\mathrm{T} 4$ to $25.6 \%$.

The results obtained applying the $M_{1}$ model to the classification of the samples clearly showed the difference in the quality of the VOCs emitted at T1 (fresh wood) and in the subsequent steps ( $\mathrm{T}_{2}$ to $\mathrm{T} 4$ ).

The $M 2$ model adopted to determine hardwood vs. softwood samples at T4 using 6 Latent Vectors showed mean sensitivity and specificity values of 1 and 0.98 , respectively. The mean classification error was 0.01 . The mean percentage of correct classification was determined to be equal to $100 \%$ for the calibration/validation set at $\mathrm{T}_{3}$ and $\mathrm{T}_{4}$, whereas at $\mathrm{T}_{2}$ it decreased to $84.6 \%$ and at $\mathrm{T}_{1}$ to $66.7 \%$. The $\mathrm{M}_{2}$ model used 9 Latent Vectors to discriminate the 9 families and showed mean sensitivity and specificity values of 0.9 and 1 , respectively. The mean classification error was equal to 0.08 . The mean percentage of correct classification was found to be equal to $84.6 \%$ for the calibration/validation set at $\mathrm{T} 4$, while at $\mathrm{T}_{3}$ it decreased to $79.5 \%$, then at $\mathrm{T}_{2}$ it drastically decreased to $20.5 \%$, and at $\mathrm{T} 1$ to $7.7 \%$. Then, to discriminate the 13 species, M2 used 8 Latent Vectors and showed mean sensitivity and specificity values of 1 and 0.9 , respectively. The mean classification error was equal to 0.03 . The mean percentage of correct classification was determined to be equal to $80.8 \%$ for the calibration/validation set (at T4), whereas at T3 it decreased to $74.4 \%$, then at $T_{2}$ it drastically decreased to $20.5 \%$, and at $\mathrm{T} 1$ to $7.7 \%$.

The performance indicators of the PLSDA model $M_{3}$ built on $66.7 \%$ of the full dataset and tested on the remaining $33.3 \%$ are reported in Tab. 2. The $M_{3}$ model adopted to determine hardwood vs. softwood sam- ples using 6 Latent Vectors showed mean sensitivity and specificity values of 1 . The mean classification error was 0 . The mean percentage of correct classification was found to be equal to $100 \%$ for both the calibration/validation and the test sets. The M3 model adopted to discriminate the 9 families used 15 Latent Vectors and showed mean sensitivity and specificity values of 0.88 and 0.93 , respectively. The mean classification error was equal to 0.10 . The mean percentage of correct classification was observed to be equal to $82.6 \%$ for the calibration/validation set and $67.3 \%$ for the test set. The M3 model adopted to discriminate the 13 species used 17 Latent Vectors and showed mean sensitivity and specificity values of 0.89 and 0.93 , respectively. The mean classification error was equal to 0.10 . The mean percentage of correct classification was found to be equal to $78.9 \%$ for the calibration/validation set and $73.1 \%$ for the test set.

Tab. 3 and Tab. 4 show the classification test set results for the $M_{3}$ families and species, respectively, reported as a confusion matrix. Each row of the square matrix represents the instances in the actual class (i.e., observed), while each column of the matrix represents the instances in the predicted class. Each entry, then, gives the number of instances of real classes that were classified as the predicted class. As a result, all correct classifications are on the main diagonal of the matrix; any value off that diagonal is an incorrect classification observation. The accuracy of the statistical classification of the model is evaluated by two different measures, the producer's accuracy (PA) and the user's accuracy (UA), reported in Tab. 5 and Tab. 6. The PA of a category indicates to what extent the reference samples of the category are correctly classified, whereas the UA of a category represents to what extent the other

Tab. 4 - Confusion matrix for the $13 \mathrm{M}_{3}$ species test set. Correct classification of wood samples are on the main diagonal of the matrix, while any value off the diagonal represents an incorrectly classified observation.

\begin{tabular}{|c|c|c|c|c|c|c|c|c|c|c|c|c|c|c|c|}
\hline & & & & & & & & edicte & d speci & & & & & & \\
\hline PLS & DA model M3 & s: & $\underline{2}$ & 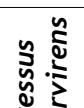 & $\underline{\underline{s}}$ & $\tilde{\Xi}$ & 章 & $\breve{s}$ & $\cong \stackrel{n}{5}$ & 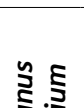 & 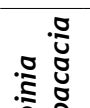 & $\underline{3}$ & క气 : & 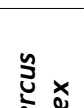 & $\pi$ \\
\hline & Cedrus atlantica & 4 & 0 & 0 & 0 & 0 & 0 & 0 & 0 & 0 & 0 & 0 & 0 & 0 & 4 \\
\hline & Pinus nigra & 0 & 4 & 0 & 0 & 0 & 0 & 0 & 0 & 0 & 0 & 0 & 0 & 0 & 4 \\
\hline & Cupressus sempervirens & 0 & 0 & 3 & 0 & 0 & 0 & 0 & 0 & 0 & 1 & 0 & 0 & 0 & 4 \\
\hline & Laurus nobilis & 0 & 0 & 0 & 4 & 0 & 0 & 0 & 0 & 0 & 0 & 0 & 0 & 0 & 4 \\
\hline & Juglans regia & 0 & 0 & 0 & 0 & 4 & 0 & 0 & 0 & 0 & 0 & 0 & 0 & 0 & 4 \\
\hline$\frac{\pi}{u}$ & Populus nigra & 0 & 0 & 0 & 0 & 0 & 2 & 0 & 0 & 0 & 1 & 0 & 0 & 1 & 4 \\
\hline$\frac{\varpi}{n}$ & Ficus carica & 0 & 0 & 0 & 0 & 0 & 1 & 2 & 0 & 0 & 1 & 0 & 0 & 0 & 4 \\
\hline$\frac{\sim}{\pi}$ & Prunus amygdalus & 0 & 0 & 0 & 0 & 0 & 0 & 0 & 0 & 0 & 1 & 3 & 0 & 0 & 4 \\
\hline 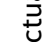 & Prunus avium & 0 & 0 & 0 & 0 & 0 & 0 & 0 & 0 & 4 & 0 & 0 & 0 & 0 & 4 \\
\hline & Robinia pseudoacacia & 0 & 0 & 0 & 0 & 0 & 0 & 0 & 0 & 1 & 2 & 1 & 0 & 0 & 4 \\
\hline & Quercus cerris & 0 & 0 & 0 & 0 & 0 & 0 & 0 & 0 & 1 & 0 & 3 & 0 & 0 & 4 \\
\hline & Quercus pubescens & 0 & 0 & 0 & 0 & 0 & 0 & 0 & 0 & 0 & 2 & 0 & 2 & 0 & 4 \\
\hline & Quercus ilex & 0 & 0 & 0 & 0 & 0 & 0 & 0 & 0 & 0 & 0 & 0 & 0 & 4 & 4 \\
\hline & Total & 4 & 4 & 3 & 4 & 4 & 3 & 2 & 0 & 6 & 8 & 7 & 2 & 5 & 52 \\
\hline
\end{tabular}


Tab. 5 - Producer accuracy (PA) and user accuracy (UA) for families based on the M3 model.

\begin{tabular}{lrr}
\hline Family & $\begin{array}{r}\text { PA } \\
\text { (\%) }\end{array}$ & $\begin{array}{r}\text { UA } \\
\text { (\%) }\end{array}$ \\
\hline Pinaceae & 75 & 100 \\
Cupressaceae & 75 & 100 \\
Lauraceae & 100 & 80 \\
Juglandaceae & 100 & 100 \\
Salicaceae & 50 & 67 \\
Moraceae & 50 & 40 \\
Rosaceae & 50 & 57 \\
Fabaceae & 25 & 34 \\
Fagaceae & 75 & 56 \\
\hline
\end{tabular}

categories are less misclassified into the category in question.

The two matrices return an accurate representation of statistical classification, and incorrect classifications based on the $M_{3}$ model occur especially for the Fabaceae family (PA $=25 \%$ and $U A=33.3 \%$ ) and regarding species as Prunus amygadalus (PA = 0\% - Tab. 5 and Tab. 6).

In Tab. 7, the protonated measurement masses presenting high VIP scores for taxonomic, families, or species discrimination based on the three different models are shown. In particular, it is worth noting that the chemical species with higher significance for hardwoods and softwoods discrimination in the $M 1$ model were $\mathrm{m} / \mathrm{z}=$ 81.070 (TI: monoterpene fragment) and $\mathrm{m} / \mathrm{z}=205.195$ (TI: sesquiterpenes), but in the other two models these masses were no longer suitable for taxonomic discrimination. On the other hand, compounds with higher VIP value that are able to discriminate families and species, both in M1 and $\mathrm{M}_{2}$ models and in some cases also in the $\mathrm{M}_{3}$ model, are $\mathrm{m} / \mathrm{z}=33.033$ (Tl: methanol), $\mathrm{m} / \mathrm{z}=43.050$ (Tl: alkyl fragment), $\mathrm{m} / \mathrm{z}$ $=45.033$ (Tl: acetaldehyde), $\mathrm{m} / \mathrm{z}=47.049$ (TI: ethanol), $\mathrm{m} / \mathrm{z}=61.028$ ( $\mathrm{Tl}$ : acetic acid), and $\mathrm{m} / \mathrm{z}=123.116$ (sesquiterpene fragment).

The M1 model confirms that VOC emissions tend to decrease with time; in fact, green wood samples are characterized by a multiplicity of compounds not present or negligible in wood after a few moisture cycles. Softwoods and hardwoods are still discerned (>79\% for all sampling-analysis time), whereas the predictive capability for families, and especially for species, drastically decreases even as soon as T2. Even applying the $\mathrm{M} 2$ model, it is possible to distinguish between softwoods and hardwoods with a mean \% value of at least $66.7 \%$ for T1; nevertheless, this model is able to identify families and species with a mean \% value higher than $50 \%$ only at the T3 sampling time.

The $M_{3}$ model maintains an accurate predictive capacity only because it also contains the data obtained with measurements carried out on fresh wood, in the absence of which the prediction capability of the models becomes very poor (as shown by Model 2).

Despite the usefulness of the three models in using VOCs as a possible tool for iden-
Tab. 6 - Producer accuracy (PA) and user accuracy (UA) for species based on the M3 model.

\begin{tabular}{lrr}
\hline Species & $\begin{array}{r}\text { PA } \\
\text { (\%) }\end{array}$ & $\begin{array}{r}\text { UA } \\
\text { (\%) }\end{array}$ \\
\hline Cedrus atlantica & 100 & 100 \\
Pinus nigra & 100 & 100 \\
Cupressus sempervirens & 75 & 100 \\
Laurus nobilis & 100 & 100 \\
Juglans regia & 100 & 100 \\
Populus nigra & 50 & 67 \\
Ficus carica & 50 & 100 \\
Prunus amygdalus & 0 & - \\
Prunus avium & 100 & 67 \\
Robinia pseudoacacia & 50 & 25 \\
Quercus cerris & 75 & 43 \\
Quercus pubescens & 50 & 100 \\
Quercus ilex & 100 & 80 \\
\hline
\end{tabular}

tifying species, families, or groups, the statistical analysis clearly showed the significant difference between the measurements at T1 (green wood) and the measurements after a few cycles of moisture variation ( $\mathrm{T} 2$ to $\mathrm{T} 4$ ).

In particular, the results of this study indicate that after the first cycles, both softwood and hardwood species tend to converge towards a common class of compounds, but a small residue of terpenes persists in the case of softwoods. It seems that green wood is still rich in compounds originated from physiological activity of the tree. Furthermore, it seems that the majority of these compounds are very volatile and, during moisture cycles, the

Tab. 7 - Protonated masses having VIP scores higher than 2 (in italic) among the three PLSDA models.

\begin{tabular}{|c|c|c|c|c|c|c|c|c|c|}
\hline \multirow{3}{*}{$\begin{array}{l}\text { Protonated } \\
\text { measured } \\
\mathrm{m} / \mathrm{z}\end{array}$} & \multicolumn{9}{|l|}{ VIP scores } \\
\hline & \multicolumn{3}{|l|}{ M1 } & \multicolumn{3}{|l|}{ M2 } & \multicolumn{3}{|l|}{ M3 } \\
\hline & $\begin{array}{c}\text { Hard/ } \\
\text { softwood }\end{array}$ & Families & Species & $\begin{array}{c}\text { Hard/ } \\
\text { softwood }\end{array}$ & Families & Species & $\begin{array}{c}\text { Hard/ } \\
\text { softwood }\end{array}$ & Families & Species \\
\hline 27.022 & 0.969 & 0.855 & 0.918 & 1.776 & 2.508 & 2.056 & 0.745 & 1.712 & 1.703 \\
\hline 33.033 & 0.582 & 3.462 & 3.039 & 3.391 & 2.348 & 3.569 & 1.172 & 1.933 & 1.947 \\
\hline 39.020 & 1.238 & 0.803 & 1.129 & 1.682 & 3.152 & 3.166 & 0.835 & 1.928 & 2.475 \\
\hline 41.038 & 1.288 & 0.757 & 0.722 & 1.911 & 2.531 & 2.259 & 1.253 & 1.524 & 1.521 \\
\hline 45.033 & 1.057 & 2.511 & 2.169 & 1.528 & 3.772 & 4.372 & 0.799 & 1.927 & 2.238 \\
\hline 47.049 & 1.011 & 2.083 & 3.908 & 1.657 & 5.002 & 3.686 & 1.081 & 2.761 & 2.970 \\
\hline 49.011 & 0.492 & 3.944 & 3.351 & 0.000 & 0.000 & 0.000 & 0.582 & 3.334 & 2.308 \\
\hline 53.040 & 1.266 & 0.932 & 1.308 & 1.773 & 2.434 & 1.883 & 1.338 & 1.612 & 1.803 \\
\hline 55.055 & 1.290 & 0.839 & 1.142 & 1.491 & 4.360 & 3.819 & 1.219 & 1.996 & 2.135 \\
\hline 59.049 & 1.144 & 0.782 & 0.624 & 1.751 & 3.430 & 3.005 & 1.072 & 2.158 & 2.633 \\
\hline 61.028 & 0.453 & 2.829 & 4.059 & 2.889 & 3.712 & 3.963 & 0.809 & 2.344 & 2.888 \\
\hline 69.069 & 1.290 & 0.774 & 0.989 & 1.865 & 2.560 & 1.978 & 1.295 & 1.406 & 1.638 \\
\hline 77.038 & 1.281 & 0.819 & 1.152 & 1.549 & 2.150 & 2.063 & 1.196 & 1.473 & 1.636 \\
\hline 79.054 & 1.359 & 1.050 & 0.874 & 2.793 & 1.743 & 1.822 & 1.542 & 1.592 & 1.571 \\
\hline 81.070 & 2.363 & 2.565 & 2.822 & 1.997 & 2.351 & 1.877 & 1.649 & 1.990 & 1.883 \\
\hline 89.059 & 0.880 & 1.201 & 1.563 & 0.000 & 0.000 & 0.000 & 0.766 & 2.007 & 1.558 \\
\hline 91.054 & 0.923 & 1.399 & 1.380 & 1.857 & 4.842 & 3.371 & 1.399 & 2.086 & 2.198 \\
\hline 95.086 & 1.192 & 0.792 & 0.786 & 2.291 & 2.957 & 1.626 & 1.770 & 1.543 & 1.358 \\
\hline 107.085 & 0.413 & 2.913 & 2.839 & 0.000 & 0.000 & 0.000 & 0.758 & 1.302 & 2.074 \\
\hline 123.116 & 1.133 & 3.301 & 3.287 & 2.245 & 3.005 & 2.804 & 1.088 & 2.948 & 2.597 \\
\hline 137.137 & 1.270 & 0.734 & 0.892 & 1.791 & 2.448 & 2.023 & 1.387 & 1.389 & 1.862 \\
\hline 153.126 & 0.929 & 0.869 & 0.912 & 0.000 & 0.000 & 0.000 & 0.784 & 2.095 & 1.767 \\
\hline 169.090 & 0.944 & 2.018 & 1.299 & 0.000 & 0.000 & 0.000 & 0.655 & 0.709 & 1.134 \\
\hline 189.165 & 2.228 & 2.669 & 3.134 & 0.000 & 0.000 & 0.000 & 1.054 & 1.141 & 1.609 \\
\hline 203.180 & 2.084 & 1.856 & 2.865 & 0.000 & 0.000 & 0.000 & 1.185 & 1.145 & 1.303 \\
\hline 205.195 & 2.489 & 2.364 & 3.319 & 0.000 & 0.000 & 0.000 & 1.224 & 1.404 & 1.791 \\
\hline
\end{tabular}


residual compounds measured can be correlated to the processes of structural modification of the cell walls. This explanation is confirmed by studies carried out on aged wood that show a lower content of hemicellulose and a significant reduction of its hygroscopicity (Obataya 2007). This analysis of VOCs indicates that such process starts when the first drying of wood occurs, and the tests on extractives and microbial-free wood allows us to exclude the influence of these two factors on the products emitted.

In this study, moisture cycles were used to simulate and accelerate a natural wood process which occurs gradually over time, with a rate that can change according to wood species and timber thickness. Further investigation are required in order to assess whether water and moisture changes inside wood have an active role in the alteration of polymers. However, despite the fact that heat treatment changes the composition of wood permanently and modifies the emission of VOCs from the material (e.g., increasing the emission of furfural that is the main thermal degradation product of hemicellulose), it is interesting to compare our results with those obtained by Manninen et al. (2002) and Hyttinen et al. (2010) on Norway spruce (Picea abies), Scot pine (Pinus sylvestris), and European aspen (Populus tremula). In their works, they demonstrated that the emissions of terpenes from softwoods and aldehydes from hardwoods decrease significantly after heat treatment. Assuming that the heat treatment produces an extreme and very intense ageing of wood, this confirms the trend showed by our results and clearly attests to the loss of these compounds by different wood species during normal ageing of wood.

\section{Conclusions}

Our results showed that, as a consequence of the moisture cycles applied, the spectra of VOC emissions from wood were significantly changed. Emission rates of all observed compounds decreased after only a few moisture (ageing) cycles. Moreover, we did not observe any increase in the emissions of specific compounds or the presence of new compounds during the simulated ageing.

The statistical analysis showed that the two PLSDA models ( $M 1$ and $M 2$ ) based on a single set of measurements ( $\mathrm{T}_{1}$ and $\mathrm{T} 4$, respectively) were not suitable for discriminating among groups of aged wood samples (hardwoods vs. softwoods, families and species), whereas using the $M_{3}$ model allowed to correctly discriminate between softwoods and hardwoods. This depends on the fact that the $M_{3}$ model also contains the data set acquired at T1 (green wood), combined with the other 3 datasets ( $\left.T_{2}, T_{3}, T_{4}\right)$.

During the moisture cycles, wood VOC emissions were subjected to quantitative and qualitative modification of the ac- quired spectra in all the species studied. Apparently, losing the compounds produced by the metabolic activity of the tree, the wood emits compounds that possibly stem from structural changes and degradation processes of the main polymers constituting the cell wall. These polymers are common to all wood species, with slight differences in their chemical composition. These results clearly indicate that the analysis of VOCs might be applied to the identification of wood species only on very fresh wood, when the wood material still contains all the classes of compounds characterized by strong volatility. As soon as the natural cycle of variation in the moisture content (i.e. moisture desorption and adsorption) begins, the composition of emissions changes, making wood identification by VOCs very hard even at the highest hierarchical level of taxa (i.e., families).

The results of this study do not clarify the role of water in the observed processes. Further studies are needed to elucidate if water can be considered only as a VOC carrier or it has an active role in the hydrolysis of wood polymers (or both of these processes). Specific treatments (Soxhlet extraction and UV treatment) applied to a separate and supplementary set of samples of Norway spruce (Picea abies) allowed us to exclude the potential effect of microbiological activity or extractives on the observed results.

In this study both the nature and the amount of VOCs emitted by wood at different times seem to indicate that the native organization of the wooden structural polymers (i.e., cellulose, hemicellulose, lignin, and their reciprocal bonding) starts to be modified immediately after the first exposure to the external environment, initiating a process of ageing that can affect the physical, mechanical, and acoustical properties of wood, and whose practical consequences are only recognizable over very long periods of time.

Extending the analysis of VOCs by PTRTOF-MS on increasingly aged and naturally aged wood samples, will help verify the presence of new signals to be possibly matched with specific degradation processes of wood components.

\section{Acknowledgements}

Part of this study was funded by the project “ALForLab" (PON03PE_00024_1) co-funded by the Italian National Operational Programme for Research and Competitiveness (PON R\&C) 2007-2013, through the European Regional Development Fund (ERDF) and the national resource Revolving Fund - Cohesion Action Plan (CAP) MIUR.

\section{References}

Akahoshi H, Obotaya E (2015). Effects of wet-dry cycling on the mechanical properties of Arundo donax L. used for the vibrating reed in woodwind instruments. Wood Science and Technology 49 (6): 1171-1183. - doi: 10.1007/soo226-015-
0760-6

Atkinson R, Arey J (2003). Atmospheric degradation of volatile organic compounds. Chemical reviews 103 (12): 4605-4638. - doi: 10.1021/cro2 06420

Baumann MGD, Batterman SA, Zhang GZ (1999). Terpene emissions from particleboard and medium-density fiberboard products. Forest Products Journal 49 (1): 49-56. [online] URL: http://search.proquest.com/openview/5d3020a ofoze033doca0389f9cob9658/1

Blake RS, Monks PS, Ellis AM (2009). Protontransfer reaction mass spectrometry. Chemical Reviews 109 (3): 861-896. - doi: 10.1021/cr800 3649

Cappellin L, Biasioli F, Granitto PM, Schuhfried E, Soukoulis C, Costa F, Märk TD, Gasperi F (2011). On data analysis in PTR-TOF-MS: from raw spectra to data mining. Sensors and Actuators B: Chemical 155 (1): 183-190. - doi: 10.1016/j.snb.20 10.11.044

Cappellin L, Loreto F, Aprea E, Romano A, Sánchez del Pulgar J, Gasperi F, Biasioli F (2013). PTR-MS in Italy: a multipurpose sensor with applications in environmental, agri-food and health science. Sensors 13 (9): 11923-11955. - doi: $10.3390 / \mathrm{s} 130911923$

Chong IG, Jun CH (2005). Performance of some variable selection methods when multicollinearity is present. Chemometrics and Intelligent Laboratory Systems, 78(1), pp. 103-112. - doi: 10.1016/j.chemolab.2004.12.011

Fengel D, Wegener G (1989). Wood: chemistry, ultrastructure, reactions. Walter de Gruyter, Berlin, Germany - New York, USA, pp. 108.

Fernández de Simón B, Esteruelas E, Muñoz ÁM, Cadahía E, Sanz M (2009). Volatile compounds in acacia, chestnut, cherry, ash, and oak woods, with a view to their use in cooperage. Journal of Agricultural and Food Chemistry 57 (8): 32173227. - doi: 10.1021/jf803463h

Filella I, Wilkinson MJ, Llusia J, Hewitt CN, Penuelas J (2007). Volatile organic compounds emissions in Norway spruce (Picea abies) in response to temperature changes. Physiologia Plantarum 130 (1): 58-66. - doi: 10.1111/j.13993054.2007.00881.x

Flamini G, Tebano M, Cioni PL, Ceccarini L, Ricci AS, Longo I (2007). Comparison between the conventional method of extraction of essential oil of Laurus nobilis L. and a novel method which uses microwaves applied in situ, without resorting to an oven. Journal of Chromatography A 1143 (1-2): 36-40. - doi: 10.1016/j.chroma. 2007.01.031

Grabmer W, Kreuzwieser J, Wisthaler A, Cojocariu C, Graus M, Rennenberg $H$, Steigner D, Steinbrecher R, Hansel A (2006). VOC emissions from Norway spruce (Picea abies L. [Karst]) twigs in the field - Results of a dynamic enclosure study. Atmospheric Environment 40: 128-137. - doi: 10.1016/j.atmosenv.2006.03.043 Guenther A, Geron C, Pierce T, Lamb B, Harley P, Fall $R$ (2000). Natural emissions of non-methane volatile organic compounds, carbon monoxide, and oxides of nitrogen from North America. Atmospheric Environment 34 (12-14): 2205-2230. - doi: 10.1016/S1352-2310(99)00465-3 Han KH, Zhang JS, Wargocki P, Knudsen HN, Guo $B$ (2010). Determination of material emission signatures by PTR-MS and their correlations 
with odor assessments by human subjects. Indoor Air 20 (4): 341-354. - doi: 10.1111/j.16000668.2010.00662.x

Herbig J, Müller M, Schallhart S, Titzmann T, Graus M, Hansel A (2009). On-line breath analysis with PTR-TOF. Journal of Breath Research 3 (2): 27004. - doi: 10.1088/1752-7155/3/2/027004

Holzinger R, Sandoval-Soto L, Rottenberger S, Crutzen PJ, Kesselmeier J (2000). Emissions of volatile organic compounds from Quercus ilex L. measured by proton transfer reaction mass spectrometry under different environmental conditions. Journal of Geophysical Research: Atmospheres 105: 573-579. - doi: 10.1029/2000J D900296

Hyttinen M, Masalin-Weijo M, Kalliokoski P, Pasanen $P$ (2010). Comparison of VOC emissions between air-dried and heat-treated Norway spruce (Picea abies), Scots pine (Pinus sylvestris) and European aspen (Populus tremula) wood. Atmospheric Environment 44 (38): 50285033. - doi: 10.1016/j.atmosenv.2010.07.018 Infantino A, Aureli G, Costa C, Taiti C, Antonucci F, Menesatti P, Pallottino F, De Felice S, D'Egidio MG, Mancuso S (2015). Potential application of PTR-TOFMS for the detection of deoxynivalenol (DON) in durum wheat. Food Control 57: 96-104. - doi: 10.1016/j.foodcont.2015.03.047 Jantunen M, Jaakkola JJ, Krzyzanowski M (1997). Assessment of exposure to indoor air pollutants. Report no. 78, WHO Regional Office Europe, Copenhagen, Denmark, pp. 139. [online] URL: http://books.google.com/books? id $=5 a 4 U 86 z \quad 9 S w C$

De Jong S (1993). SIMPLS: an alternative approach to partial least squares regression. Chemometrics and Intelligent Laboratory Systems 18 (3): 251-263. - doi: 10.1016/0169-7439 (93)85002-x

Karl T, Guenther A, Spirig C, Hansel A, Fall R (2003). Seasonal variation of biogenic VOC emissions above a mixed hardwood forest in northern Michigan. Geophysical Research Letters, 30 (23): 2186. - doi: 10.1029/2003GL018432 Kennard RW, Stone LA (1969). Computer aided design of experiments. Technometrics 11 (1): 137-148. - doi: 10.2307/1266770

Lanza M, Acton WJ, Sulzer P, Breiev K, Jürschik S, Jordan A, Hartungen E, Hanel G, Märk L, Märk TD, Mayhew CA (2015). Selective reagent ionisation-time of flight-mass spectrometry: a rapid technology for the novel analysis of blends of new psychoactive substances, Journal of Mass Spectrometry 50 (2): 427-431. - doi: 10.1002/jms.3514

Mancuso S, Taiti C, Bazihizina N, Costa C, Menesatti P, Giagnoni L, Arenella M, Nannipieri P,
Renella G (2015). Soil volatile analysis by proton transfer reaction-time of flight mass spectrometry (PTR-TOF-MS). Applied Soil Ecology 86: 182-191. - doi: 10.1016/j.apsoil.2014.10.018 Manninen AM, Pasanen P, Holopainen JK (2002). Comparing the $\mathrm{VOC}$ emissions between airdried and heat-treated Scots pine wood. Atmospheric Environment 36 (11): 1763-1768. - doi: 10.1016/S1352-2310(02)00152-8

Obataya E (2007). Effects of ageing and heating on the mechanical properties of wood. In: Proceedings of the Cost Action IE0601 International Conference "Wood Science for Conservation of Cultural Heritage". Florence (Italy) 8-10 Nov 2007. Firenze University Press, Florence, Italy, pp. 16-23. - doi: 10.1400/141799

Risholm-Sundman $M$, Lundgren $M$, Vestin $E$, Herder P (1998). Emissions of acetic acid and other volatile organic compounds from different species of solid wood. Holz Als Roh-Und Werkstoff 56 (2): 125-129. - doi: 10.1007/s0010 70050282

Roffael E (2006). Volatile organic compounds and formaldehyde in nature, wood and wood based panels. Holz als Roh- und Werkstoff 64 (2): 144-149. - doi: 10.1007/s00107-005-0061-0 Roffael E, Schneider T, Dix B (2015). Effect of oxidising and reducing agents on the release of volatile organic compounds (VOCs) from strands made of Scots pine (Pinus sylvestris L.). Wood Science and Technology 49 (5): 957-967. - doi: 10.1007/s00226-015-0744-6

Sabatier R, Vivien M, Amenta P (2003). Two approaches for discriminant partial least squares. In: Proceedings of the $26^{\text {th }}$ Annual Conference of the Gesellschaft für Klassifikation e.V. "Between Data Science and Applied Data Analysis" (Schader M, Gaul W, Vichi M eds). University of Mannheim (Germany) 22-24 Jul 2002. Springer, Berlin, Heidelberg, Germany, pp. 100-108. - doi: 10.1007/978-3-642-18991-3_12

Salem MZM, Böhm M (2013). Understanding of formaldehyde emissions from solid wood: an overview. BioResources 8 (3): 4775-4790. [online] URL: http://ojs.cnr.ncsu.edu/index.php/ BioRes/article/view/4170

Schumann A, Lenth C, Hasener J, Steckel V (2012). Detection of volatile organic compounds from wood-based panels by gas chromatography-field asymmetric ion mobility spectrometry (GC-FAIMS). International Journal for Ion Mobility Spectrometry 15 (3): 157-168. - doi: 10.1007/s12127-012-0103-3

Sjöström M, Wold S, Söderström B (1986). PLS discrimination plots. In: "Pattern Recognition in Practice II" (Gelsema ES, Kanals LN eds). Elsevier, Amsterdam, Netherlands, pp. 461-470.
- doi: 10.1016/B978-0-444-87877-9.50042-X Soukoulis C, Cappellin L, Aprea E, Costa F, Viola R, Märk TD, Gasperi F, Biasioli F (2013). PTR-ToFMS, a novel, rapid, high sensitivity and noninvasive tool to monitor volatile compound release during fruit post-harvest storage: the case study of apple ripening. Food and Bioprocess Technology 6 (10): 2831-2843. - doi: 10.1007 /s11947-012-0930-6

Steckel V, Welling J, Ohlmeyer M (2010). Emissions of volatile organic compounds from convection dried Norway spruce timber. In: Proceedings of the Final Conference of COST Action $\mathrm{E}_{53}$ "The future of quality control for wood and wood products". Edinburgh (UK) 4-7 May 2010. Edinburgh Napier University, Forest Products Research Institute / Centre for Timber Engineering, pp. 222-230. [online] URL: http:// timberdry.net/downloads/EDG-Workshop-Edin burgh/Edinburgh-Presentation/15.pdf

Taiti C, Costa C, Guidi Nissim W, Bibbiani S, Azzarello E, Masi E, Pandolfi C, Pallottino F, Menesatti P, Mancuso S (2016). Assessing VOC emission by different wood cores using the PTRToF-MS technology. Wood Science and Technology. 1-23. - doi: 10.1007/s00226-016-0866-5

Taiti C, Costa C, Menesatti P, Comparini D, Bazihizina N, Azzarello E, Masi E, Mancuso S (2015). Class-modeling approach to PTR-TOFMS data: a peppers case study. Journal of the Science of Food and Agriculture 95 (8): 1757-1763. - doi: 10.1002/jsfa.6761

Vita F, Taiti C, Pompeiano A, Bazihizina N, Lucarotti V, Mancuso S, Alpi A (2015). Volatile organic compounds in truffle (Tuber magnatum Pico): comparison of samples from different regions of Italy and from different seasons. Scientific Reports 5: 1262910. - doi: 10.1038/srep12629 WHO (1989). Indoor air quality: organic pollutants. In: Proceedings of the World Health Organization (WHO) Meeting. Berlin (Germany) 23-27 August 1987. World Health Organization, Regional Office for Europe, EURO Reports and Studies 111, Copenhagen, Denmark, pp. 1-70.

\section{Supplementary Material}

Tab. S1 - Main compounds identified via PTR-TOF-MS during first measurement: Protonated masses (mass/charge $=\mathrm{m} / \mathrm{z}$ ), molecular formula, tentative identification, references of the investigated volatile compounds emitted from different wood species.

Link: Sassoli_2259@supploo1.pdf 